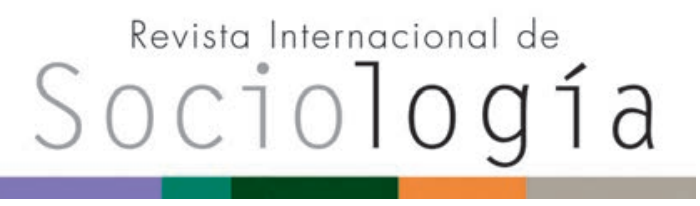

Revista Internacional de Sociología RIS vol. 75 (2), e060, abril-junio, 2017, ISSN-L:0034-9712 doi: http://dx.doi.org/10.3989/ris.2017.75.2.15.103

\title{
PRIMERA APROXIMACIÓN A LA CONSTRUCCIÓN DE UNA ESCALA DE ADHESIÓN A LOS PRINCIPIOS DEL DERECHO PENAL (EAPDP). Estudio piloto en el Conurbano del Gran Concepción, Chile
}

Pablo Javier Fuentealba Carrasco

Departamento de Sociología. Universidad de Concepción, Chile

pablofuentealba1@gmail.com

ORCID iD: http://orcid.org/0000-0002-5965-0556

OMAR A. BARRIGA

Departamento de Sociología. Universidad de Concepción, Chile

obarriga@udec.cl

ORCID iD: http://orcid.org/0000-0002-5786-8287

Cómo citar este artículo / Citation: Fuentealba Carrasco, P. J. y O. A. Barriga. 2017. "Primera aproximación a la construcción de una Escala de Adhesión a los Principios del Derecho Penal (EAPDP). Estudio piloto en el Conurbano del Gran Concepción, Chile". Revista Internacional de Sociología 75 (2): e060. doi: http://dx.doi.org/10.3989/ ris.2017.75.2.15.103

\section{Resumen}

El artículo presenta las propiedades psicométricas a nivel exploratorio de la "Escala de Adhesión a los Principios del Derecho Penal" de un estudio piloto aplicado a una muestra consecutiva de 369 casos en el conurbano del Gran Concepción, Chile. Se describe la construcción del instrumento y su estructura, centrándose en la exposición de las propiedades de validez de constructo a través del AFE y de validez convergente por medio de una correlación inversa con la escala de Percepción de Inseguridad. Para establecer confiabilidad, se presenta el Alpha de Cronbach para la Escala General y para cada subescala generada. Se concluye con los alcances, limitaciones, proyecciones de la escala, así como las sugerencias para su ampliación y la necesidad de aplicación en otros contextos, puesto que el estudio es una primera aproximación al fenómeno.
PRELIMINARY APPROACH TO THE CONSTRUCTION OF A SCALE OF ADHERENCE TO THE PRINCIPLES OF CRIMINAL LAW (SAPCL). A pilot study in the Greater Metropolitan area of Concepción, Chile
Copyright: @ 2017 CSIC. Este es un artículo de acceso abierto distribuido bajo los términos de la licencia Creative Commons Attribution (CC BY) España 3.0.

Recibido: 14/03/2015. Aceptado: 15/02/2017 Publicado on line: 24/05/2017

\section{Abstract}

The article presents the psychometric properties of the "Scale of adherence to the principles of Criminal Law" of a pilot study applied to a consecutive sample of 369 cases in the Greater Metropolitan Area of Concepción, Chile. The logic behind the construction of the instru-ment and its structure is described, focusing on expos-ing the properties of construct validity through EFA and convergent validity through an inverse correlation with a scale of perceived insecurity. In terms of reliability, we present Cronbach's Alpha for the General Scale and for each subscale generated. It concludes with the scope, limitations and projections of the scale, as well as suggestions for its expansion and potential for application in other contexts.

\section{Palabras Clave}

Actitudes punitivas; Análisis factorial; Derechos fundamentales; Legitimidad; Sociología del Derecho.

\section{KEYWORDS}

Factor Analysis; Fundamental Rights; Legitimacy; Punitive Attitudes; Sociology of Law. 


\section{INTRODUCCIÓN}

Con el fin de proteger a la persona humana y sus derechos fundamentales frente a la eventual violencia punitiva estatal, el Derecho Penal moderno ha elaborado un núcleo de garantías en materia penal y procesal-penal inspiradas en un conjunto de nociones doctrinales que pueden entenderse como los principios del derecho penal liberal (presunción de inocencia, principio de legalidad, humanidad de las penas, derecho a defensa, in dubio pro reo, entre otros). Estos orientaron las legislaciones en la mayor parte de las democracias liberales occidentales y se encuentran, en mayor o menor grado, incorporados en el ordenamiento legal en lo penal (Silva 1992; Ruiz 1997; Etcheberry 1998; Zaffarroni 2001; Bustos y Hormazábal 2004).

Pero ¿se adhiere la ciudadanía a este conjunto de principios penales y procesal-penales que informa la legislación? Esta pregunta plantea el problema del consenso o disenso por parte de la población en general en torno a un conjunto de creencias que justifique la obediencia a los mandatos legales. Así, implica la cuestión de la legitimidad ante el sistema jurídico-penal en su nivel más profundo, ya que los principios jurídicos constituyen el fundamento doctrinal del orden legal y, podríamos considerar que, en términos de Ortega y Gasset (2005), se encontrarían en el plano de las ideas y creencias de la sociedad. En consecuencia, medir la adhesión a los principios penales no implicaría conocer la aceptación o rechazo de normas particulares por parte de la ciudadanía (ley de aborto, pena de muerte, etc.), sino el consenso o disenso ante las bases del ordenamiento penal en general de las sociedades demoliberales y, por lo tanto, la creencia en la validez del Estado de derecho con las consiguientes consecuencias para la seguridad jurídica (Bacigalupo 2005). Esto fundamenta la importancia de un estudio de este tipo.
Para responder a esta pregunta se desarrolló un estudio piloto consistente en la elaboración de una "Escala de Adhesión a los Principios del Derecho Penal (EAPDP)", compuesta inicialmente de 50 ítems, la cual fue aplicada a una muestra consecutiva de 369 casos en el Gran Concepción, pero bastante heterogénea en términos sociodemográficos. Mediante Análisis Factorial Exploratorio (AFE) se construyeron seis subescalas que, a nivel descriptivo, mostrarían niveles insuficientes de consenso (inferiores al 50\%) en torno a estos principios penales, reflejando así problemas de legitimidad ante las bases del ordenamiento penal (Tabla I).

Para respaldar estos resultados es fundamental describir la construcción de la escala, sus características y propiedades métricas exploratorias, para así conocer sus alcances, limitaciones y proyecciones en futuras investigaciones. Por ello, este artículo se centra en la exposición de:

a) El proceso de construcción del instrumento, su estructura y sus características,

b) Análisis de eliminación de ítems,

c) Las evidencias de validez exploratoria (no confirmatorias) obtenidas mediante el $A F E$, con la conceptualización de los factores y la construcción de las subescalas,

d) Las evidencias de validez convergente mediante la correlación inversa con la variable de Percepción de Inseguridad,

e) La consistencia interna de la Escala General y de las subescalas mediante Alpha de Cronbach.

Teóricamente el estudio recoge elementos provenientes del derecho, la psicología y la sociología jurídico-criminal. El derecho proporcionó el conjunto de conceptos (principios penales y procesal-penales) con los que se trabajó para ser medidos y que fueron operacionalizados en el instrumento. Si bien

Tabla I.

Adhesión a los Principios del Derecho Penal por Subescala y Escala General ${ }^{1}$

\begin{tabular}{|c|c|c|c|c|c|c|c|}
\hline Subescalas y Escala General & Muy Baja & Baja & $\begin{array}{l}\text { Ni Alta, } \\
\text { Ni Baja }\end{array}$ & Alta & Muy Alta & M & DE \\
\hline Adhesión al Principio de Gradualidad de la Pena & $26,9 \%$ & $27,7 \%$ & $13,8 \%$ & $22,8 \%$ & $8,7 \%$ & 2,59 & 0,93 \\
\hline $\begin{array}{l}\text { Adhesión al Derecho, al Debido Proceso y Personalidad } \\
\text { de la Pena }\end{array}$ & $9,0 \%$ & $18,4 \%$ & $17,1 \%$ & $32,4 \%$ & $23,0 \%$ & 3,40 & 0,68 \\
\hline $\begin{array}{l}\text { Adhesión al Principio de Intervención Mínima y Legalidad } \\
\text { en la Aplicación de Penas y Medidas }\end{array}$ & $32,9 \%$ & $33,2 \%$ & $15,2 \%$ & $12,2 \%$ & $6,4 \%$ & 2,26 & 0,69 \\
\hline $\begin{array}{l}\text { Adhesión al Principio de Humanidad de las Penas desde } \\
\text { un Sistema Estatal de Justicia }\end{array}$ & $10,8 \%$ & $18,6 \%$ & $17,9 \%$ & $30,8 \%$ & $21,8 \%$ & 3,34 & 0,88 \\
\hline Adhesión al Principio de Legalidad Penal & $21,9 \%$ & $30,9 \%$ & $15,9 \%$ & $20,1 \%$ & $11,1 \%$ & 2,68 & 0,94 \\
\hline $\begin{array}{l}\text { Adhesión a los Derechos Sociales y de Trato a los Con- } \\
\text { denados y Acusados }\end{array}$ & $13,2 \%$ & $18,8 \%$ & $20,2 \%$ & $29,1 \%$ & $18,7 \%$ & 3,24 & 0,80 \\
\hline Escala General (EAPDP) & $18,8 \%$ & $24,3 \%$ & $16,6 \%$ & $25,0 \%$ & $15,4 \%$ & 2,92 & 2,88 \\
\hline
\end{tabular}


la literatura no difería mayormente en la conceptualización de los principios, se encontraron diferencias en su clasificación de acuerdo a los diversos autores (Cury y Urzúa 1982; Silva 1992; Ruiz 1997; Etcheberry 1998; Bustos y Hormazábal 2004; Bacigalupo 2005;) o en el ordenamiento nacional (Código Penal 2009; Código Procesal-Penal 2010) e internacional (Convención Americana sobre Derechos Humanos de 1969; Pacto de Derechos Civiles y Políticos de 1966). Esto impidió elaborar una categorización a priori de principios penales y procesal-penales, por lo cual fueron concebidos de forma independiente para generar a posteriori -por medio del AFE- categorías que resultaran coherentes con la teoría penal.

Desde la psicología y la sociología se asumió una concepción integradora del término "actitud" a partir de diversos autores (Katz y Stotland 1959, en Summers 1978; Fishbein y Ajzen 1975, en Pademo y García 2001; Rodrígues et al. 2002; Vieytes 2004), siendo esta entendida como una predisposición cognitiva, afectiva y/o conductual del individuo hacia un objeto (material o abstracto) y que se manifiesta en contextos determinados. De esta forma, al integrar el concepto de actitud con el de "principio penal/ procesal-penal", la variable Adhesión a los Principios del Derecho Penal (APDP) la definimos conceptualmente como el nivel en el que los principios penales y procesal-penales han sido incorporados subjetivamente (nivel cognitivo, afectivo y conductual) por los individuos, siendo aceptados, comprendidos y considerados válidos y legítimos por estos, convirtiéndose en reglas generales de razonamiento para interpretar y juzgar situaciones jurídicas y orientar acciones en base a estos mismos principios. Operacionalmente, fue medida a través de una escala tipo Likert.

Teóricamente es posible pensar en diferentes correlatos y/o predictores vinculados a la APDP (victimización, actitudes punitivas, etc.). Sin embargo, en este estudio, con el objetivo de establecer validez convergente (como forma de validez de constructo), hipotetizamos una correlación inversa entre APDP y Percepción de Inseguridad (PI), ya que, en términos funcionalistas, la PI podría asociarse con la capacidad del Estado (percibida) para cumplir con las funciones de orden y seguridad, ya que los principios garantistas se interpretarían como barreras para el ejercicio de esta función.

Metodológicamente la investigación contribuye con la disciplina al proporcionar una escala que permitiría conocer el nivel de consenso/disenso hacia los fundamentos del sistema penal y que dispondría de propiedades de confiabilidad y validez exploratoria para medir esta variable; algo que, a la fecha, no se ha hecho aún, siendo la primera aproximación al fenómeno. Conocer esto resulta fundamental, puesto que las propiedades métricas nos permiten saber si estamos midiendo aquello que afirmamos medir y con qué error de medición (fundamental para respal- dar cualquier resultado posterior), lo cual se torna especialmente necesario en ciencias humanas cuando medimos constructos (entendidos como conceptos o variables que no existen físicamente, tales como la inteligencia o la personalidad; por lo tanto difíciles de medir). Si bien la escala es perfectible y estamos en presencia de un estudio que requiere ser replicado en otros contextos para efectos confirmatorios, el instrumento proporcionaría un primer modelo al cual podrían incorporarse otros principios penales no medidos en esta escala y/o ser una guía para conocer la adhesión hacia principios jurídicos de otras ramas del Derecho (laboral, tributario, etc.). Disciplinariamente, el tema reviste especial importancia, puesto que se vincula con el problema de la legitimidad en torno a las bases del sistema jurídico, y porque permite conocer las relaciones entre sociedad, cultura y derecho desde la opinión pública (Fucito 1999; Ferrari 2012). Esto permitiría abrir un nuevo ámbito en el área de la sociología jurídica y criminal que regularmente se ha centrado en el estudio de las actitudes punitivas, la percepción de inseguridad, o bien en la aceptación/rechazo de normas y/o principios aislados, pero no en el estudio del consenso o disenso en torno a los fundamentos generales y más básicos del ordenamiento legal. Por ello, disponer de instrumentos con propiedades métricas adecuadas para medir este constructo resulta esencial para el desarrollo de la sociología empírica del derecho.

\section{Método}

\section{Diseño}

Se usó un enfoque cuantitativo, transversal y no experimental, con datos primarios recogidos bajo el método de encuesta, usando un cuestionario estandarizado (las mismas preguntas y respuestas cerradas) como instrumento.

\section{Muestra}

Los datos fueron recolectados en diciembre de $2014^{2}$. Se utilizó una muestra consecutiva, recogida mediante punto fijo en diversas áreas de la ciudad y compuesta por 369 entrevistados, mayores de 18 años, pertenecientes al Conurbano del Gran Concepción, Región del Bío-Bio, Chile. Esta conurbación es la segunda de mayor población en Chile después del Gran Santiago y contaría con 1.040.348 habitantes para el año 2015 (Instituto Nacional de Estadísticas 2016). El tamaño muestral fue calculado al 95\% de nivel de confianza y $5,1 \%$ de margen de error para lograr obtener adecuados niveles de potencia muestral ${ }^{3}$.

Las edades de los entrevistados fluctúan entre los 18 y 81 años, con una media de 35,8 años y una $D E=15,3$ años, pertenecientes a diversos niveles socioeconómicos (alto/medio alto/medio/medio bajo). 
Un $50,7 \%$ de la muestra se encuentra entre los 18 y los 29 años, un $19,7 \%$ entre 30 y 44 años, un $21,4 \%$ entre 45 y 59 años y un $8,4 \%$ de 60 años o más. Un $45 \%$ son hombres. El $14,3 \%$ se autodefine como derecha/centro-derecha, un $12,8 \%$ centro, un $29 \%$ centro izquierda/centro-izquierda y un $43,9 \%$ apolítico/sin ubicación. Un 2,4\% no tiene ningún tipo de estudios, o bien posee solo Estudios Básicos incompletos/completos, un $23,6 \%$ tiene Estudios Medios completos/incompletos, un $10 \%$ cuenta con Estudios Técnicos completos/incompletos, un 13\% Educación Técnica Profesional incompleta/completa y un $46,9 \%$ Estudios Universitarios completos/incompletos. Finalmente, un $3,1 \%$ posee Estudios de Postgrado completos/incompletos.

Abad et al. (2011) consideran esencial que exista variabilidad en las dimensiones medidas y señalan que la muestra debería ser representativa de la población respecto a la cual busca generalizar los resultados. En nuestro caso, al no ser una muestra probabilística no es posible generalizar los resultados -no hay garantías de su representatividad-, lo cual constituye una de las principales limitaciones de la investigación. Sin embargo, esta es adecuada en tamaño y suficientemente heterogénea, puesto que los principales grupos -considerando su composición sociodemográfica y política- se encuentran representados en la muestra, lo cual, si bien no permite la generalización, contribuye a la variabilidad en las respuestas. En consecuencia, las nuevas investigaciones debieran efectuarse utilizando muestras probabilísticas.

\section{Instrumento}

Se construyó un cuestionario para medir la "Adhesión a los Principios del Derecho Penal”. Inicialmente, este contaba con 50 reactivos tipo Likert para medir directamente el consenso en torno a 23 principios penales y procesal-penales, e indirectamente 3 principios. La adhesión no se midió abstractamente, sino vinculando cada principio a delitos de alta connotación social, los que fueron clasificados en dos niveles polares: alto rechazo social (homicidio, pedofilia y violación) y bajo rechazo social (hurtos, cuento del tío, carterazos, lanzazos, entre otros ${ }^{4}$ ). Los delitos considerados en cada ítem se presentaban como ejemplos de cada nivel para el entrevistado, más que como referencia a delitos específicos, con la finalidad de evaluar la adhesión en dos contextos polares diferentes. De esta forma, el entrevistado debía señalar su nivel de acuerdo o desacuerdo ante las afirmaciones planteadas (con cinco categorías de respuesta: desde 'Muy en Desacuerdo' hasta 'Muy de Acuerdo'). Estas afirmaciones conjugaban el principio penal con los delitos clasificados en ambos niveles. Como consecuencia, cada principio medido poseía su par lógico de reactivos.

Se usaron los mismos ejemplos de delitos en todas las afirmaciones para no perder la equivalencia entre los ítems. Considerando que la población ge- neral estudiada carecía de conocimientos jurídicos especializados y podía desconocer los principios penales, así como los conceptos y términos legales ("irretroactividad", "taxatividad", "hurto", "imputado"), los reactivos se tradujeron desde el lenguaje técnico al lenguaje coloquial y corriente, formulándose como expresiones accesibles a sujetos de diversos niveles educacionales. Se procuró que cada ítem contuviera el concepto del principio que se buscaba medir. Como ejemplo, los reactivos quedaron formulados del siguiente modo (principio de legalidad, como máxima taxatividad interpretativa):

21.-Si la pena máxima que establece la ley para un robo sin violencia, mecheo, cuento del tío o lanzazo es considerada baja por los jueces del caso, deberían aplicar un castigo más alto aunque signifique salirse de la ley.

36.-Si la pena máxima que establece la ley para una violación, homicidio o pedofilia es considerada baja por los jueces del caso, deberían aplicar un castigo más alto aunque signifique salirse de la ley.

Posteriormente, los ítems fueron distribuidos aleatoriamente en el cuestionario. Los delitos de 'rechazo social intermedio' (como robo con violencia y asaltos, delito de lesiones) se excluyeron con el fin de reducir la extensión del cuestionario y, además, para evitar la posible ambigüedad entre el nivel intermedio y los polos extremos de delitos usados. La escala no incorpora delitos cuya respuesta pudiese encontrarse condicionada por variables político-valóricas (delitos de consumo y/o tráfico de drogas, terrorismo, estafas de grandes empresas), ya que estas no fueron controladas en la investigación, optándose por aquellos delitos que presentaban un rechazo transversal.

Los principios medidos en la escala fueron: 1) culpabilidad, 2)distinción de responsabilidad entre adultos y adolescentes, 3 ) trayectoria criminal (irreprochable conducta anterior) 4) reparación del daño causado, 5) plena prueba (y duda razonable), 6) derecho de defensa material, 7) derecho a defensa técnica, 8) derecho a jueces imparciales, 9) jueces independientes, 10) legalidad de la prueba, 11) personalidad o intrascendencia de la pena, 12) presunción de inocencia, 13) carga de la prueba, 14) gradualidad de la pena, 15) peligrosidad, 16) subsidiariedad sancionatoria, 17) humanidad de las penas, 18) control de la ejecución penal, 19) sistema estatal de justicia, 20) legalidad penal como máxima taxatividad penal, e 21) interpretativa, 22) derechos sociales de los acusados y 23) rigor probatorio. Otros principios no medidos directamente, pero implícitos en los reactivos, fueron 'reserva legal en lo penal', 'irretroactividad penal' e 'in dubio pro reo'. Además, si bien para cada principio se disponía de ítems específicos destinados para su medición, algunos fueron evaluados a través de múltiples reactivos. También, muchos eran ítems complejos porque medían principalmente un rasgo, pero indirectamente podían referir a otros principios penales y vincularse con otros conceptos. 
Para establecer "validez de contenido" (previa a la recolección de datos), el instrumento fue sometido al juicio de expertos para su revisión y validación; de los cuales 6 eran especialistas en el ámbito jurídico y 3 especialistas en metodología (provenientes del ámbito de la psicología y de la sociología). Los jueces estimaron pertinentes los ítems propuestos a través de la escala. Con los resultados y las sugerencias cualitativas recogidas durante el procedimiento, el instrumento fue perfeccionado hasta obtener la versión para aplicar.

\section{Lectura de ítems}

Los ítems se encuentran redactados tanto en sentido positivo como inverso para evitar el sesgo por respuesta automática (aquiescencia). Sin embargo, antes de someter las preguntas a tratamiento estadístico, algunas fueron recodificadas de tal manera que, para todas ellas, valores cercanos a 1 indicaran baja adhesión y cercanos a 5 alta adhesión.

La respuesta intermedia ( $\mathrm{Ni}$ de acuerdo, ni en desacuerdo) fue interpretada como baja adhesión, ya que, en términos kantianos, los principios penales son estrictos en lo referente a su exigencia de universalidad (Kant 1873 y 1989). De este modo, se estima que una adecuada adhesión debiese considerar únicamente las respuestas 'De acuerdo' o 'Muy de acuerdo' como indicadores de consenso. Sin embargo, nos mantenemos abiertos a otras posibles interpretaciones.

De esta forma, actitudinalmente, los reactivos incorporan el aspecto cognitivo (creencias, conocimiento y valoraciones del principio penal), emocional (que surge al asociar el principio con un delito) y conductual (opinión sobre la acción del juez, tribunales, "la justicia", etc.). La distancia hacia el objeto se establece con la posición de acuerdo/desacuerdo ante la afirmación.

\section{Construcción de la escala}

Con posterioridad a la recolección de datos, la primera etapa consistió en la eliminación de ítems donde se contemplaron criterios teóricos y estadísticos. La tasa de no respuesta fue baja $(\leq 0,6 \%)$.

Teóricamente, para mantener un ítem, se consideró que fuese conceptualmente necesario para medir un principio jurídico-penal relevante. Además, cada reactivo fue evaluado considerando los coeficientes de su par lógico (delito de alto y/o bajo rechazo social). No se podía eliminar un solo ítem, sino la pareja de reactivos para no perder la coherencia lógica de la escala que medía la adhesión en estos dos contextos polares.

Se efectuó el siguiente análisis estadístico de ítems: a) Inspección visual de los resultados descriptivos para detectar variabilidad en las respuestas. No se identificaron ítems con baja variabilidad o tasa de respuesta. Las desviaciones estándar más altas y más bajas de los reactivos fueron de 2,24 y 1,10 respectivamente (Anexos I-VI).

b) Se atendió a los valores de asimetría superiores a 1,0 y, únicamente, se identificaron 4 ítems entre 1,0 y 1,5 y uno entre 1,5 y 2,0 . estos se mantuvieron en el modelo por no alejarse considerablemente de la distribución normal. Además, porque el elevado número de ítems no afectaría al $A F E$.

c) Se aplicó un análisis de discriminación mediante comparación de grupos extremos usando $t$ de Student (para asimetrías bajo 1,0) y $U$ de Mann Whitney (para asimetrías sobre $1,0)$, encontrándose diferencias significativas $(p<0,001)$ para todos los ítems al comparar el cuartil superior con el inferior.

d) Se evaluó la fiabilidad para todos los ítems con Alpha Cronbach $(\alpha=0,904)$. En este análisis, la matriz de correlaciones no presentó correlaciones ínter-ítem sobre 0,900, por lo cual no sospechamos sobreestimación en la consistencia interna por medición de un mismo rasgo. La correlación-elemento-totalcorregida identificó valores bajo 0,200 (entre 0,150 y 0,200 ), pero no bajo 0,150 . Sin embargo, en algunos casos, su par lógico ('bajo' o 'alto rechazo social') presentaba correlaciones sobre $0,300 \mathrm{y}$, en otras, levemente superiores a 0,200 . Se consideraron como eliminables aquellos ítems bajo 0,200 , pero cuyo par lógico superara levemente el 0,200. En alpha-si-se-elimina-el-elemento no se detectó claramente qué reactivos podían eliminarse debido al elevado número de ítems, ya que la mayoría mantenían la fiabilidad sin aumentarla considerablemente. Por ello, solo se consideraron aquellos cuya eliminación aumentara la fiabilidad y/o la mantuviera.

e) Finalmente, el Análisis Factorial Exploratorio (AFE) preliminar con Ejes Principales y rotación Promax fue decisivo, ya que identificó 3 ítems con cargas inferiores a 0,300 en la Matriz de Estructura.

Como consecuencia de esto se eliminaron 4 ítems que medían "carga de la prueba (2 y 16)" y "gradualidad de la pena/beneficios" (ítems 28 y 41)".

En una segunda etapa, una vez eliminados los ítems, se realizó el AFE definitivo con 46 reactivos $\left(7,61\right.$ casos por ítem $\left.{ }^{5}\right)$. Para AFE se recomienda un mínimo de 5 e idealmente sobre 10 casos por reactivo. Si bien nuestro número no es muy alto y podría considerarse una limitación, es suficiente para efectuar AFE. 
Para interpretar los factores, se atendió a la Matriz de Estructura $(M E)$, considerando como criterio que los ítems presentaran cargas superiores a 0,300 , que el factor presentara, al menos, dos ítems con cargas sobre 0,700 , y/o bien cuatro superiores a 0,400 para mantener el factor.

Para interpretar la Matriz de Configuración (MC), se exigieron los mismos criterios requeridos en la $\mathrm{ME}$, pero se mantuvieron ítems con cargas entre 0,100 y 0,300 cuando se cumplieran los siguientes requisitos:

a) Que el promedio de carga con su par lógico (delito de alto o bajo rechazo social) presentase una carga aceptable (sobre 0,320) para no perder la coherencia en la medición (en la cual cada ítem se encuentra pareado).

b) Que la correlación-ítem-escala-total-corregida fuese superior a 0,200.

c) Que en alpha-si-se-elimina-el-ítem la consistencia no se viese sensiblemente perjudicada con la mantención del ítem.

De esta forma, la posible inclusión de un ítem con carga bajo 0,300 en la MC se aceptó excepcionalmente (reactivos 13, 23 y 40) en la medida en que se cumplieron estos requisitos.

Para la interpretación del Alpha de Cronbach de cada subescala se utilizaron los criterios de George y Mallery (en Gliem y Gliem 2003) y la teoría fue considerada como el criterio de decisión principal (cuando esta no contraviniera los datos).

Finalmente, los reactivos de cada factor/subescala fueron sometidos de forma independiente a un Análisis Paralelo de Horn. Se determinó un único factor a retener, revelándose la unidimensionalidad en cada subescala sin que en estas se identificaran nuevos subfactores/subdimensiones.

\section{Resultados}

Para establecer validez factorial exploratoria y conocer la multidimensionalidad de la escala, se realizó un AFE. La extracción se realizó mediante Ejes Principales con rotación Promax. Se encontraron 9 correlaciones entre factores con fuerzas sobre 0,32 (Anexos), por lo cual se mantuvo la rotación oblicua. Los resultados preliminares de la Tabla II muestran un buen ajuste de los datos en términos de adecuación muestral $(K M O=0,831$; Prueba de Esfericidad de Bartlett $\mathrm{p} \leq 0,001)$.

El Scree Test y el Análisis Paralelo de Horn determinaron seis factores a retener que explican el $45,1 \%$ de la varianza inicial y un $37,4 \%$ después de la rotación (Tabla II). Si bien la Varianza Total Explicada (VTE) no es muy elevada, esto puede comprenderse porque la escala presenta un elevado número de ítems (46) reducidos a 6 factores. Considerando que se trata de un primer estudio, es posible afirmar que el modelo logra reducir suficientemente (no idóneamente) la dimensionalidad del fenómeno, ya que logra explicar una buena proporción de la variabilidad (50\% aprox.) en seis factores. Esto indica que el poder explicativo de los factores es suficiente, pero no óptimo. Mejoramientos de la escala debiesen intentar aumentar la VTE.

La Escala General de APDP presenta una fiabilidad $\alpha=0,906$, considerada excelente (46 ítems). Los datos de la Escala General y de las Subescalas se distribuyen normalmente, ya que a pesar de que en la prueba $K-S$ dos variables presentan significancias menores a 0,05 , esta prueba resulta ser extremadamente sensible a las desviaciones de la normalidad (Pardo \& San Martín 2010). Por ello, hemos aceptado asimetrías entre $\pm 1,0$. Las cargas factoriales en la Matriz de Estructura (ME) y de Configuración (MC) presentan valores óptimos de acuerdo al cuadro de resumen (Tabla II).

Tabla II.

Resumen propiedades psicométricas para Escala General y Subescalas: cargas factoriales, fiabilidad y distribución de los datos

\begin{tabular}{lccccccc}
\hline $\begin{array}{l}\text { Escala General APDP y Sub- } \\
\text { escalas (de Adhesión a...) }\end{array}$ & $\begin{array}{c}\mathbf{V T E}^{*} \\
(\%)\end{array}$ & $\begin{array}{c}\text { (ME) Rangos Cargas } \\
\text { Factoriales }\end{array}$ & $\begin{array}{c}\text { (MC) Rangos Cargas } \\
\text { Factoriales }\end{array}$ & $\begin{array}{c}\alpha \\
\text { Cronbach }\end{array}$ & K-S & Asim. & Curt. \\
\hline Gradualidad de la Pena & $\begin{array}{r}20,0- \\
18,71\end{array}$ & $0,575-0,758$ & $0,419-0,817$ & 0,865 & 0,302 & 0,252 & $-0,386$ \\
\hline $\begin{array}{l}\text { Derecho al Debido Proceso y } \\
\text { Personalidad de la Pena }\end{array}$ & $\begin{array}{r}8,17- \\
6,98\end{array}$ & $0,351-0,701$ & $0,165-0,674$ & 0,797 & 0,164 & $-0,215$ & $-0,219$ \\
\hline $\begin{array}{l}\text { Limitación y Legalidad en la } \\
\text { aplicación de Medidas y Penas }\end{array}$ & $\begin{array}{r}4,98- \\
3,64\end{array}$ & $0,369-0,606$ & $0,118-0,597$ & 0,720 & 0,000 & 0,783 & 0,947 \\
\hline $\begin{array}{l}\text { Humanidad de las Penas desde } \\
\text { un Sistema Estatal de Justicia }\end{array}$ & $\begin{array}{r}4,37- \\
\text { 2,96 }\end{array}$ & $0,586-0,666$ & $0,539-0,625$ & 0,781 & 0,101 & $-0,178$ & $-0,438$ \\
\hline Principio de Legalidad Penal & $\begin{array}{r}4,2- \\
2,83\end{array}$ & $0,458-0,813$ & $0,315-0,757$ & 0,810 & 0,000 & $-0,411$ & $-0,560$ \\
\hline $\begin{array}{l}\text { Derechos Sociales y de Trato a } \\
\text { condenados y acusados }\end{array}$ & $\begin{array}{r}3,44- \\
2,28\end{array}$ & $0,397-0,563$ & $0,383-0,520$ & 0,676 & 0,137 & $-0,041$ & $-0,316$ \\
\hline Escala General APDP (totales) & $\begin{array}{r}45,17- \\
37,4\end{array}$ & $0,485-0,668$ & $0,421-0,651$ & 0,906 & 0,583 & $-0,247$ & 0,325 \\
\hline
\end{tabular}

*VTE Inicial-Rotación 


\section{La Escala general de APDP}

A partir del AFE se elaboró la Escala General de APDP $^{6}$ que está conformada por seis subescalas que son de adhesión a: 1) la Gradualidad de la Pena, 2) el Derecho al Debido Proceso y Personalidad de la Pena, 3) la Limitación y Legalidad en la Aplicación de Medidas y Penas, 4) la Humanidad de las Penas desde un Sistema Estatal de Justicia, 5) el Principio de Legalidad Penal y 6) los Derechos Sociales y Trato a Condenados y Acusados.

A continuación presentamos a) los pesos factoriales de la Matriz de Estructura (ME) y de Configuración $(M C)^{7}$, b) a si-se-elimina-el-ítem en relación a la Subescala y, finalmente, c) la correlación-ítemescala-total-corregida (ri-t) en relación a la Escala General de APDP y a las Subescalas.

\section{Subescala 1: "Gradualidad de la Pena"}

El primer factor obtenido permitió generar la Subescala 1 (8 ítems) que explica un 20\% de la varianza y posee una consistencia interna $\alpha=0,865$ considerada buena (Tabla III). En la ME las cargas factoriales oscilan entre 0,575 y 0,758 . Con el control de los restantes factores, en la $M C$ este rango se modifica levemente asumiendo valores entre 0,419 y 0,817 (Tabla III).

En términos de su conceptualización teórica, el factor es homologable con el concepto de "Adhesión a la Gradualidad de la Pena". Resulta concordante con la teoría penal liberal que reconoce diferenciaciones o gradaciones al momento de establecer la responsabilidad y aplicar la sanción en oposición a las penas indiferenciadas. De este modo, la subescala construida permite conocer en qué grado el sujeto acepta que las penas y/o medidas en el ius puniendi deban aplicarse de acuerdo a un sistema de graduación o proporcionalidad, reconociendo agravantes y atenuantes, así como distintos tipos de responsabilidad penal en función de la etapa de desarrollo psicológico del individuo (menores podrían tener dificultades para discernir, y/o identificar posibles cursos de acción), distinción culpa/dolo, trayectoria criminal y/o acciones reparatorias.

Tabla III.

Confiabilidad y validez de subescala de Adhesión a la Gradualidad de la Pena

\begin{tabular}{|c|c|c|c|c|c|}
\hline & \multicolumn{2}{|c|}{ AFE } & \multicolumn{3}{|c|}{ Confiabilidad } \\
\hline & ME & MC & $\begin{array}{l}\text { ri-t } \\
\text { Escala } \\
\text { Gral. }\end{array}$ & $\begin{array}{l}\text { ri-t Sub } \\
\text { escala }\end{array}$ & $\begin{array}{l}\text { a si se } \\
\text { elimina } \\
\text { ítem }\end{array}$ \\
\hline $\begin{array}{l}\text { 43.-Considero que ante delitos como el homicidio, la pedofilia o la violación, un ado- } \\
\text { lescente de entre 14-17 años tiene la misma responsabilidad que un adulto y debería } \\
\text { recibir el mismo tipo de castigo. }\end{array}$ & 0,565 & 0,419 & 0,402 & 0,537 & 0,857 \\
\hline $\begin{array}{l}\text { 47.-Considero que ante delitos como robo sin violencia, cuento del tío, estafa telefóni- } \\
\text { ca, mecheo, un adolescente de entre } 14-17 \text { años tiene la misma responsabilidad que } \\
\text { un adulto y debería recibir el mismo tipo de castigo. }\end{array}$ & 0,623 & 0,526 & 0,372 & 0,590 & 0,852 \\
\hline $\begin{array}{l}\text { 44.-Considero que ante delitos como el homicidio, la pedofilia o la violación, alguien } \\
\text { que actuó intencionalmente tiene la misma responsabilidad que alguien que actuó sin la } \\
\text { intención (porque fue imprudente, o por ignorancia) y debería recibir el mismo castigo. }\end{array}$ & 0,710 & 0,665 & 0,478 & 0,657 & 0,844 \\
\hline $\begin{array}{l}\text { 48.-Considero que ante delitos como robo sin violencia, cuento del tío, estafa telefóni- } \\
\text { ca, mecheo, alguien que actuó intencionalmente tiene la misma responsabilidad que } \\
\text { alguien que actuó sin la intención (porque fue imprudente, o por ignorancia) y debería } \\
\text { recibir el mismo castigo. }\end{array}$ & 0,758 & 0,766 & 0,460 & 0,689 & 0,841 \\
\hline $\begin{array}{l}\text { 45.-Considero que ante delitos como el homicidio, la pedofilia o la violación, se deben } \\
\text { aplicar castigos a todos por igual, sin diferenciar entre alguien que tiene un historial } \\
\text { criminal manchado y alguien con sus antecedentes limpios. }\end{array}$ & 0,698 & 0,765 & 0,332 & 0,625 & 0,848 \\
\hline $\begin{array}{l}\text { 49.-Considero que ante delitos como robo sin violencia, cuento del tío, estafa telefóni- } \\
\text { ca, mecheo, se deben aplicar castigos a todos por igual, sin diferenciar entre alguien } \\
\text { que tiene un historial criminal manchado y alguien con sus antecedentes limpios. }\end{array}$ & 0,755 & 0,817 & 0,365 & 0,665 & 0,843 \\
\hline $\begin{array}{l}\text { 46.-Considero que ante delitos como el homicidio, la pedofilia o la violación, se debe } \\
\text { juzgar o aplicar castigos a todos por igual, sin diferenciar si el delincuente realizó ac- } \\
\text { ciones positivas que pueden favorecerlo (por ejemplo, ayudó a la víctima, se entregó a } \\
\text { la policía, colaboró con la justicia, intentó reparar el daño causado, etc.) }\end{array}$ & 0,575 & 0,555 & 0,372 & 0,539 & 0,857 \\
\hline $\begin{array}{l}\text { 50.-Considero que ante delitos como robo sin violencia, cuento del tío, estafa telefónica, } \\
\text { mecheo, se debe juzgar o aplicar castigos a todos por igual, sin diferenciar si el delin- } \\
\text { cuente realizó acciones positivas que pueden favorecerlo (por ejemplo, ayudó a la vícti- } \\
\text { ma, se entregó a la policía, colaboró con la justicia, intentó reparar el daño causado, etc.) }\end{array}$ & 0,662 & 0,695 & 0,342 & 0,620 & 0,848 \\
\hline
\end{tabular}




\section{Subescala 2: Adhesión al Derecho al Debido Proceso y Personalidad de la Pena}

El segundo factor obtenido permitió generar la Subescala 2 (12 ítems) que explica un $8,17 \%$ de la varianza total, con una fiabilidad aceptable $\alpha=0,797$, pero muy próxima a buena (Tabla III). En la ME los pesos factoriales oscilan entre 0,351 y 0,701 y en la $M C$ las cargas presentan valores entre 0,165 y 0,674 (Tabla IV).

El factor es homologable con el concepto de "Adhesión al Debido Proceso y Personalidad de la Pena". Permite conocer en qué grado el sujeto acepta que en el procedimiento penal se incorpore un conjunto de derechos y garantías, tales como el derecho a defensa material, imparcialidad (como equidistancia del juez hacia las partes) e independencia de los jueces en la decisión (que no intervenga la voluntad de un poder externo o superior en la decisión judicial), legalidad en la obtención de la prueba y la exigencia de plena prueba como criterio de condena (duda razonable). Con posterioridad al proceso, mide el consenso en torno al principio de personalidad de la pena (intrascendencia) ${ }^{8}$.

Adicionalmente, los cuatro primeros principios se vinculan con la presunción de inocencia (se midió implícita y transversalmente en este conjunto de reactivos), puesto que el 'Debido Proceso' busca evitar que se produzca el falso positivo (que un inocente sea declarado culpable).

Tabla IV.

Confiabilidad y validez de subescala de Adhesión al Derecho al Debido Proceso y Personalidad de la Pena

\begin{tabular}{|c|c|c|c|c|c|}
\hline & \multicolumn{2}{|c|}{ AFE } & \multicolumn{3}{|c|}{ Confiabilidad } \\
\hline & ME & MC & $\begin{array}{l}\text { ri-t } \\
\text { Escala } \\
\text { Gral. }\end{array}$ & $\begin{array}{c}\text { ri-t Sub } \\
\text { escala }\end{array}$ & $\begin{array}{l}\text { a si se } \\
\text { elimina } \\
\text { ítem }\end{array}$ \\
\hline $\begin{array}{l}\text { 3.-Cuando finaliza un juicio por homicidio, violación o pedofilia, los jueces debe- } \\
\text { rían castigar a un acusado cuando hay más probabilidades de que sea culpable, } \\
\text { aunque puedan existir ciertas dudas fundadas de que tal vez no cometió el delito. }\end{array}$ & 0,439 & 0,340 & 0,426 & 0,433 & 0,783 \\
\hline $\begin{array}{l}\text { 31.-Cuando finaliza un juicio por robo sin violencia, mecheo, lanzazo o cuento del } \\
\text { tío, los jueces deberían castigar a un acusado cuando hay más probabilidades de } \\
\text { que sea culpable, aunque puedan existir ciertas dudas fundadas de que tal vez no } \\
\text { cometió el delito. }\end{array}$ & 0,466 & 0,316 & 0,490 & 0,436 & 0,783 \\
\hline $\begin{array}{l}\text { 4.-En los juicios por robo sin violencia, mecheo, cuento del tío o lanzazos, los jue- } \\
\text { ces deberían estar del lado de quienes acusan al sospechoso para que ganen el } \\
\text { juicio, en vez de ser objetivos y neutrales. }\end{array}$ & 0,562 & 0,569 & 0,419 & 0,445 & 0,782 \\
\hline $\begin{array}{l}\text { 18.-En los juicios por homicidio, pedofilia o violación, los jueces deberían estar } \\
\text { del lado de quienes acusan sospechoso para que ganen el juicio, en vez de ser } \\
\text { objetivos y neutrales. }\end{array}$ & 0,701 & 0,604 & 0,563 & 0,623 & 0,764 \\
\hline $\begin{array}{l}\text { 8.-Apoyaría el uso de medios ilegales (por ejemplo, escuchas no autorizadas, } \\
\text { pruebas y testigos falsos, confesiones forzadas, etc.) en un juicio si permiten que } \\
\text { se castigue a un acusado por robo sin violencia, lanzazo, mecheo o cuento del tío. }\end{array}$ & 0,526 & 0,560 & 0,432 & 0,456 & 0,781 \\
\hline $\begin{array}{l}\text { 23.-Apoyaría el uso de medios ilegales (por ejemplo, escuchas no autorizadas, } \\
\text { pruebas y testigos falsos, confesiones forzadas, etc.) en un juicio si permiten que } \\
\text { se castigue a un acusado por homicidio, pedofilia o violación. }\end{array}$ & 0,351 & 0,165 & 0,406 & 0,370 & 0,789 \\
\hline $\begin{array}{l}\text { 9.-Los familiares más cercanos de quienes han cometido delitos de violación, ho- } \\
\text { micidio o pedofilia también deberían recibir algún castigo, aunque sea menor. }\end{array}$ & 0,552 & 0,674 & 0,229 & 0,376 & 0,789 \\
\hline $\begin{array}{l}\text { 37.-Los familiares más cercanos de quienes han cometido delitos de robo sin vio- } \\
\text { lencia, cuento del tío, mecheo, lanzazo, también deberían recibir algún castigo, } \\
\text { aunque sea menor. }\end{array}$ & 0,468 & 0,452 & 0,303 & 0,409 & 0,785 \\
\hline $\begin{array}{l}\text { 11.-Los acusados por robo sin violencia, lanzazo, mecheo o cuento del tío, debe- } \\
\text { rían perder el derecho a defenderse en un juicio para ser escuchados y exponer } \\
\text { sus argumentos y pruebas. }\end{array}$ & 0,431 & 0,356 & 0,363 & 0,395 & 0,787 \\
\hline $\begin{array}{l}\text { 34.-Los acusados por violación, homicidio o pedofilia, deberían perder el derecho a } \\
\text { defenderse en un juicio para ser escuchados y exponer sus argumentos y pruebas. }\end{array}$ & 0,402 & 0,312 & 0,357 & 0,374 & 0,789 \\
\hline $\begin{array}{l}\text { 17.-Ante delitos como el robo sin violencia, mecheo, lanzazo o cuento del tío, las } \\
\text { autoridades deberían intervenir en las decisiones de los jueces para que condenen } \\
\text { a los acusados o aumenten sus castigos. }\end{array}$ & 0,551 & 0,389 & 0,529 & 0,509 & 0,776 \\
\hline $\begin{array}{l}\text { 32.-Ante delitos como homicidio, pedofilia o violación, las autoridades deberían } \\
\text { influir en las decisiones de los jueces para que condenen a los acusados o aumen- } \\
\text { ten sus castigos. }\end{array}$ & 0,450 & 0,315 & 0,417 & 0,457 & 0,781 \\
\hline
\end{tabular}




\section{Subescala 3: Adhesión a la Limitación y Legalidad en la aplicación de Medidas y Penas}

El tercer factor obtenido permitió generar la Subescala 3 compuesta por 8 ítems. Explica un 4,98\% de la varianza y posee una consistencia interna $\alpha=0,720$ considerada aceptable (Tabla III). La ME presenta pesos factoriales con valores entre 0,369 y 0,606 . Estos se modifican en la MC, presentando valores entre 0,118 y 0,597 (Tabla V).

El factor es homologable con la "Adhesión a la Limitación y Legalidad en la Aplicación de Medidas y Penas". Mide si el sujeto acepta que se respete la "presunción de inocencia" (medidas cautelares deben aplicarse bajo criterios estrictos y rigurosos de legalidad procesal, con mínima interpretación, lo que implica esencialmente el habeas corpus), el "principio de peligrosidad" (medidas no pueden ser ni más gravosas, ni de más duración que la pena abstractamente aplicable, ni exceder los límites de la pena, ni de lo necesario - principio de necesidad- para prevenir la peligrosidad del autor) y al "principio de subsidiariedad sancionatoria" (no debe acudirse a penas o sanciones graves si es suficiente con la imposición de sanciones más leves). Adicionalmente se incorpora la exigencia de "legalidad" y "rigurosidad del estándar probatorio y del procesal", independencia e imparcialidad en la decisión judicial, aspecto iden- tificable (por oposición) en los ítems asociados a la influencia de los medios de comunicación sobre la decisión del juez.

Finalmente, el que los reactivos destinados a medir peligrosidad y medidas cautelares se agrupen junto con los de subsidiariedad sancionatoria ${ }^{9}$, permite pensar que estas medidas son interpretadas por la población como sanciones penales en sí mismas.

\section{Subescala 4: Adhesión a la Humanidad de las Penas desde un Sistema Estatal de Justicia}

El cuarto factor obtenido permitió generar la Subescala 4. Contiene 6 ítems, explica un 4,37\% de la varianza y presenta una consistencia interna aceptable $(\alpha=0,781)$, aunque cercana a buena (Tabla III). Los pesos factoriales en la ME oscilan entre 0,586 y 0,666 . Con el control de los restantes factores en la MC estas se modifican levemente, oscilando entre 0,539 y 0,625 (Tabla VI).

Teóricamente el factor es homologable bajo el concepto de "Adhesión a la Humanidad de las Penas desde un Sistema Estatal de Justicia". Permite conocer en qué grado los sujetos apoyan un sistema de sanción penal basado en el "principio de humanidad de las penas" que elimine la violencia y crueldades innecesarias (torturas, degradaciones, etc.), en el

Tabla V.

Confiabilidad y validez de subescala de Adhesión a la Limitación y Legalidad en la Aplicación de Penas y Medidas

\begin{tabular}{|c|c|c|c|c|c|}
\hline & \multicolumn{2}{|c|}{ AFE } & \multicolumn{3}{|c|}{ Confiabilidad } \\
\hline & ME & MC & $\begin{array}{l}\text { ri-t } \\
\text { Escala } \\
\text { Gral. }\end{array}$ & $\begin{array}{l}\text { ri-t Sub } \\
\text { escala }\end{array}$ & $\begin{array}{l}\text { a si se } \\
\text { elimina } \\
\text { ítem }\end{array}$ \\
\hline $\begin{array}{l}\text { 10.- Si los noticiarios o los periódicos presentan antecedentes que mostrarían que } \\
\text { un sospechoso es responsable de un delito de violación, homicidio o pedofilia, los } \\
\text { jueces deberían considerar esta información para tomar su decisión. }\end{array}$ & 0,496 & 0,539 & 0,286 & 0,452 & 0,683 \\
\hline $\begin{array}{l}\text { 20.- Si los noticiarios o los periódicos presentan antecedentes que mostrarían que un } \\
\text { sospechoso es responsable de un delito de robo sin violencia, cuento del tío, lanzazo } \\
\text { o mecheo, los jueces deberían considerar esta información para tomar su decisión. }\end{array}$ & 0,545 & 0,516 & 0,419 & 0,495 & 0,674 \\
\hline $\begin{array}{l}\text { 15.- Aunque las primeras pruebas que vinculan a un sospechoso con un delito } \\
\text { de robo sin violencia, lanzazo, mecheo o cuento del tío, sean insuficientes o con- } \\
\text { tradictorias, el juez debería dejarlo preso mientras se realiza la investigación que } \\
\text { busca definir si es responsable. }\end{array}$ & 0,606 & 0,569 & 0,466 & 0,473 & 0,679 \\
\hline $\begin{array}{l}\text { 30.- Aunque las primeras pruebas que vinculan a un sospechoso con un delito de ho- } \\
\text { micidio, pedofilia o violación, sean insuficientes o contradictorias, el juez debería de- } \\
\text { jarlo preso mientras se realiza la investigación que busca definir si es responsable. }\end{array}$ & 0,585 & 0,597 & 0,355 & 0,438 & 0,686 \\
\hline $\begin{array}{l}\text { 27.- Si una persona está por terminar su encarcelamiento por violación, homicidio } \\
\text { o pedofilia, deberían aplicarle medidas de control y vigilancia de por vida. }\end{array}$ & 0,563 & 0,572 & 0,358 & 0,469 & 0,679 \\
\hline $\begin{array}{l}\text { 13.- Si una persona está por terminar su encarcelamiento por robo sin violencia, } \\
\text { lanzazo, cuento del tío o mecheo, deberían aplicarle medidas de control y vigilan- } \\
\text { cia de por vida. }\end{array}$ & 0,369 & 0,118 & 0,375 & 0,238 & 0,728 \\
\hline $\begin{array}{l}\text { 14.- Ante delitos como homicidio, pedofilia o violación, deberían aplicarse castigos } \\
\text { más drásticos aumentándose las penas. }\end{array}$ & 0,510 & 0,561 & 0,244 & 0,401 & 0,694 \\
\hline $\begin{array}{l}\text { 40.- Ante delitos como robo sin violencia, cuento del tío, lanzazo o mecheo, debe- } \\
\text { rían aplicarse castigos más drásticos aumentándose las penas. }\end{array}$ & 0,372 & 0,244 & 0,439 & 0,332 & 0,704 \\
\hline
\end{tabular}


Tabla VI.

Confiabilidad y validez de subescala de Adhesión a la Humanidad de las Penas desde un Sistema Estatal de Justicia

\begin{tabular}{|c|c|c|c|c|c|}
\hline & \multicolumn{2}{|c|}{ AFE } & \multicolumn{3}{|c|}{ Confiabilidad } \\
\hline & ME & MC & $\begin{array}{l}\text { ri-t } \\
\text { Escala } \\
\text { Gral. }\end{array}$ & $\begin{array}{l}\text { ri-t Sub } \\
\text { escala }\end{array}$ & $\begin{array}{l}\text { a si se } \\
\text { elimina } \\
\text { ítem }\end{array}$ \\
\hline $\begin{array}{l}\text { 12.-Para el robo sin violencia, lanzazo o cuento del tío, deberían existir sanciones } \\
\text { que, además de la cárcel, consistan en causarle daños psicológicos o físicos al } \\
\text { delincuente como golpes o palizas, que sean acordes a los daños causados. }\end{array}$ & 0,590 & 0,568 & 0,395 & 0,474 & 0,761 \\
\hline $\begin{array}{l}\text { 25.-Para la violación, homicidio o pedofilia, deberían existir sanciones que, } \\
\text { además de la cárcel, consistan en causarle daños psicológicos o físicos al cri- } \\
\text { minal como golpes, palizas, castración a los agresores sexuales, que sean } \\
\text { acordes a los daños causados. }\end{array}$ & 0,579 & 0,569 & 0,345 & 0,486 & 0,761 \\
\hline $\begin{array}{l}\text { 22.-Si un preso por homicidio, violación o pedofilia, es golpeado o maltratado } \\
\text { por los gendarmes, es porque en cierta medida se lo merece. }\end{array}$ & 0,666 & 0,625 & 0,463 & 0,571 & 0,738 \\
\hline $\begin{array}{l}\text { 39.-Si un preso por robo sin violencia, mecheo, lanzazo, cuento del tío, es gol- } \\
\text { peado o maltratado por los gendarmes, es porque en cierta medida se lo merece. }\end{array}$ & 0,615 & 0,618 & 0,429 & 0,493 & 0,757 \\
\hline $\begin{array}{l}\text { 24.-Ante delitos como robo sin violencia, mecheo, cuento del tío, las víctimas o } \\
\text { sus familias deberían poder tomarse la justicia por sus propias manos. }\end{array}$ & 0,650 & 0,563 & 0,521 & 0,600 & 0,731 \\
\hline $\begin{array}{l}\text { 38.-Ante delitos de pedofilia, homicidio, violación, las víctimas o sus familias } \\
\text { deberían poder tomarse la justicia por sus propias manos. }\end{array}$ & 0,586 & 0,539 & 0,432 & 0,556 & 0,742 \\
\hline
\end{tabular}

respeto a los "derechos humanos de los condenados" (que no deban sufrir maltrato físico o psicológico). Asimismo, permite conocer la adhesión ante el "Sistema Estatal de Justicia" a través del principio que reconoce la existencia de un órgano centralizado encargado de administrar justicia en contraposición a la justicia privada. Este principio está vinculado estrechamente con la legitimidad social de este rol del Estado que, desde la época moderna, adquiere esta función exclusiva, a la vez que, bajo los principios de necesidad y minimización de la violencia estatal, va sustituyendo la pena represiva, reemplazándola por una de tipo restitutiva.

\section{Subescala 5: Adhesión al Principio de Legalidad Penal}

El quinto factor obtenido permitió generar la Subescala 5, compuesta de 6 ítems, explica un 4,2\% de la varianza y posee una consistencia interna $\alpha=0,810$, considerada buena (Tabla III). La ME muestra pesos factoriales con valores entre 0,458 y 0,813 que se modifican en la $M C$ por el control de los restantes factores presentando valores entre 0,315 y 0,757 (Tabla VII).

El factor puede conceptualizarse como "Adhesión al Principio de Legalidad Penal”. Resume principios básicos del Estado de derecho conducentes a la seguridad jurídica. Permite conocer en qué medida los sujetos estiman que el ius puniendi debe desarrollarse conforme a la "legalidad penal" que exige la "máxima taxatividad penal" (delitos y penas deben encontrarse definidos por la ley vigente, clara y precisa) y "máxima taxatividad interpretativa" (la decisión judicial debe ajustarse a la legalidad, limitando la interpretación y voluntad personal del juez -puesto que no son soberanos- o de la opinión ciudadana aún no expresada mediante ley).

El factor unifica el sentido "formal" y "material" de la legalidad penal. Desde la legalidad formal mide el "principio de Reserva Legal" que establece que los delitos y las penas solo pueden regularse mediante ley previa (Nullum crimen, nulla poena sine praevia lege o de Nulla poena sine praevia lege), excluyéndose como fuente la voluntad del juez y/o la voluntad ciudadana no expresada mediante ley; el delito y su pena deben encontrarse tipificados con anterioridad al acto (irretroactividad penal). Desde la legalidad material incorpora la exigencia de máxima taxatividad penal en la creación de la ley penal, y máxima taxatividad interpretativa en el ejercicio de la justicia penal.

\section{Subescala 6: Adhesión a los derechos socia- les y de trato a condenados y acusados}

El sexto y último factor contiene 6 ítems, explica el $3,44 \%$ de la varianza y tiene una consistencia interna cuestionable $(\alpha=0,676)$, pero aproximada a aceptable (Tabla III). La ME presenta cargas factoriales entre 0,397 y 0,563 , las cuales se modifican al ser controladas por los restantes factores. En la MC estos oscilan entre 0,383 y 0,520 (Tabla VIII).

El factor seis presentó dificultades iniciales para ser conceptualizado, puesto que, desde la disciplina jurídica, los ítems presentaban mayor coherencia teórica con otros factores. Finalmente se conceptualizó como "Adhesión a los derechos sociales y de trato a condenados y acusados". Alude a un aspecto más bien "práctico" del fenómeno en términos de la acción 
jurisdiccional ejercida desde el Estado hacia acusados y condenados, de acuerdo con ciertos derechos sociales y del trato que se derivarían de los principios del derecho y que, posiblemente, presuponen costos o gastos en programas y políticas públicas. Implica que la adhesión a los Principios no solo debe mantenerse en un ámbito teórico, sino que, como consecuencia cuasi necesaria, debe expresarse en un aspecto práctico, como lo es el "derecho a defensa técnica" (derecho a un abogado y medios para defenderse, ya que la defensa material no puede realizarse sin la técnica), ciertos derechos sociales en materia penitenciaria (condiciones dignas, derechos y trato adecuado en lo penitenciario) y presunción de inocencia (no solo que se "considere" o "presuma" como inocente, sino que se "trate" como tal) ${ }^{10}$. Este ámbito constituye una extensión desde el Estado de derecho hacia el "Estado social de derecho".

Tabla VII.

Confiabilidad y Validez de subescala de Adhesión al Principio de Legalidad Penal

\begin{tabular}{|c|c|c|c|c|c|}
\hline & \multicolumn{2}{|c|}{ AFE } & \multicolumn{3}{|c|}{ Confiabilidad } \\
\hline & ME & MC & $\begin{array}{c}\text { ri-t Escala } \\
\text { Gral. }\end{array}$ & $\begin{array}{l}\text { ri-t Sub } \\
\text { escala }\end{array}$ & $\begin{array}{l}\text { a si se } \\
\text { elimina } \\
\text { ítem }\end{array}$ \\
\hline $\begin{array}{l}\text { 6.-Si la pena máxima que establece la ley para un robo sin violencia, hurto, } \\
\text { mecheo, cuento del tío o lanzazo es considerada baja por la mayoría de } \\
\text { la gente, los jueces deberían aplicar un castigo más alto aunque signifique } \\
\text { salirse de la ley. }\end{array}$ & 0,574 & 0,478 & 0,471 & 0,529 & 0,790 \\
\hline $\begin{array}{l}\text { 19.-Si la pena máxima que establece la ley para una violación, homicidio o } \\
\text { pedofilia, es considerada baja por la mayoría de la gente, los jueces deberían } \\
\text { aplicar un castigo más alto aunque signifique salirse de la ley. }\end{array}$ & 0,776 & 0,736 & 0,573 & 0,674 & 0,756 \\
\hline $\begin{array}{l}\text { 21.-Si la pena máxima que establece la ley para un robo sin violencia, me- } \\
\text { cheo, cuento del tío o lanzazo es considerada baja por los jueces del caso, } \\
\text { deberían aplicar un castigo más alto aunque signifique salirse de la ley. }\end{array}$ & 0,813 & 0,757 & 0,600 & 0,697 & 0,753 \\
\hline $\begin{array}{l}\text { 36.-Si la pena máxima que establece la ley para una violación, homicidio o } \\
\text { pedofilia, es considerada baja por los jueces del caso, deberían aplicar un } \\
\text { castigo más alto aunque signifique salirse de la ley. }\end{array}$ & 0,735 & 0,749 & 0,509 & 0,596 & 0,775 \\
\hline $\begin{array}{l}\text { 7.-En vez de ser tan precisas y detalladas las leyes para definir delitos como } \\
\text { violación, homicidio o pedofilia, deberían ser más generales y flexibles para } \\
\text { poder castigar a todo el que tenga conductas parecidas. }\end{array}$ & 0,458 & 0,315 & 0,463 & 0,449 & 0,806 \\
\hline $\begin{array}{l}\text { 35.-En vez de ser tan precisas y detalladas, las leyes para definir delitos } \\
\text { como lanzazo, mecheo, cuento del tío, deberían ser más generales y flexi- } \\
\text { bles para poder castigar a todo el que tenga conductas parecidas. }\end{array}$ & 0,507 & 0,415 & 0,456 & 0,485 & 0,798 \\
\hline
\end{tabular}

Tabla VIII.

Confiabilidad y Validez de subescala de Adhesión a los derechos sociales y de trato a condenados y acusados

\begin{tabular}{|c|c|c|c|c|c|}
\hline & \multicolumn{2}{|c|}{ AFE } & \multicolumn{3}{|c|}{ Confiabilidad } \\
\hline & ME & MC & $\begin{array}{l}\text { ri-t } \\
\text { Escala } \\
\text { Gral. }\end{array}$ & $\begin{array}{c}\text { ri-t } \\
\text { Sub } \\
\text { escala }\end{array}$ & $\begin{array}{l}\text { a si se } \\
\text { elimina } \\
\text { ítem }\end{array}$ \\
\hline $\begin{array}{l}\text { 1.-Un sospechoso por homicidio, pedofilia o violación, debe tratarse como inocente } \\
\text { por la justicia mientras un tribunal no lo declare culpable. }\end{array}$ & 0,464 & 0,383 & 0,397 & 0,410 & 0,634 \\
\hline $\begin{array}{l}\text { 29.-Un sospechoso por robo sin violencia, mecheo, lanzazo o cuento del tío, debe } \\
\text { tratarse como inocente por la justicia mientras un tribunal no declare que es culpable. }\end{array}$ & 0,397 & 0,393 & 0,199 & 0,325 & 0,659 \\
\hline $\begin{array}{l}\text { 5.-Si un acusado por homicidio, pedofilia o violación no tiene recursos, el Estado de- } \\
\text { bería asignarle un abogado y medios para que se defienda de forma gratuita. }\end{array}$ & 0,511 & 0,436 & 0,361 & 0,438 & 0,623 \\
\hline $\begin{array}{l}\text { 33.-Si un acusado por robo sin violencia, lanzazo, mecheo o cuento del tío, no tiene } \\
\text { recursos, el Estado debería asignarle un abogado y medios para que se defienda de } \\
\text { forma gratuita. }\end{array}$ & 0,507 & 0,520 & 0,197 & 0,419 & 0,630 \\
\hline $\begin{array}{l}\text { 42.-A los condenados por delitos de homicidio, pedofilia o violación, deberían mante- } \\
\text { nerlos en condiciones dignas dentro de la cárcel, respetándoles sus derechos como } \\
\text { seres humanos. }\end{array}$ & 0,563 & 0,508 & 0,369 & 0,443 & 0,622 \\
\hline $\begin{array}{l}\text { 26.-A los condenados por delitos como robo sin violencia, cuento del tío o mecheo, } \\
\text { deberían mantenerlos en condiciones dignas dentro de la cárcel, respetándoles sus } \\
\text { derechos como seres humanos. }\end{array}$ & 0,470 & 0,485 & 0,192 & 0,399 & 0,637 \\
\hline
\end{tabular}




\section{Correlaciones entre subescalas}

Para una mayor precisión en la relación lineal entre subescalas y también entre las subescalas con la Escala General, la Tabla IX presenta las correlaciones entre las escalas construidas y no entre los factores originalmente obtenidos por el $A F E^{11}$.

Se observan algunas correlaciones cercanas a despreciables (cercanas a 0,100), otras débiles $(0,200 \leq r \quad 0,300)$, y la mayoría moderadas $(0,300 r$ $\leq 0,500)$ o fuertes $(r 0,500)$ entre las subescalas (Tabla IX). Esto indica que, con mayor o menor fuerza (dependiendo de la fuerza de la correlación), quienes, por ejemplo, aceptan la 'Gradualidad de la Pena', también tienden a aceptar -por ejemplo- el 'Derecho al Debido Proceso', el 'Principio de Humanidad de las Penas' o la 'Legalidad Penal'. Inversamente, quien no adhiere a alguna de estas subescalas, tenderá a no adherir y a presentar menores puntuaciones en las subescalas.

Del mismo modo, quienes adhieren a alguna de las subescalas, tienden a adherir a la Escala General de APDP y viceversa $(r \geq 0,500)$. Esto implica que las subescalas pueden constituir buenos predictores de la adhesión general, abriendo la posibilidad futura de construir escalas abreviadas.

\section{Adhesión a los Principios del Derecho Penal y Percepción de Inseguridad $(P I)$}

Para evidencias de validez convergente, se buscó establecer una correlación inversa con la variable Percepción de Inseguridad (PI). Ésta mide 'Probabilidad estimada' (de Baja a Muy Alta) y 'Preocupación' (de Nada a Mucho) de ser víctima de alguno de los 9 delitos propuestos (asalto, robo en vehículo, delito sexual, hurto, etc.), medidas con escala tipo Likert con cinco categorías de respuesta.

La escala de PI fue sometida a AFE (con Scree Test, Análisis Paralelo, Máxima Verosimilitud). Para 'Probabilidad estimada de ser víctima', se determinó un factor a extraer (explica un 52,4\% de la varianza; cargas factoriales entre 0,779 y 0,544 ; fiabilidad $\alpha=0,884)$ para 9 ítems. Para 'Preocupación por ser víctima' también se determinó un factor a extraer (explica un $54,9 \%$ de la varianza; cargas factoriales entre 0,774 y 0,591 ; fiabilidad $\alpha=0,896$ ) para 9 ítems. Las escalas presentan una correlación moderada entre sí $(r=0,560 ; p<0,001)$. Todas presentan distribuciones normales de acuerdo a la prueba $K-S$.

$\mathrm{Si}$ bien las correlaciones entre subescalas $P I^{*} E A P D P$ no son muy altas (oscilan entre $r=-0,96^{* *}$ y $r=-0,263^{* *}$ ), todas (excepto una) son estadísticamente significativas y en la dirección hipotéticamente propuesta (Tabla X).

Se destaca que la 'Probabilidad estimada de ser víctima de un delito', presenta menor fuerza con EA$P D P(r=-0,196)$ que la 'Preocupación de ser víctima de un delito' $(r=-0,263)$. Esto indicaría que el componente afectivo-emocional en la PI podría constituir un elemento importante en la elaboración del juicio (moral), superando al componente cognitivo-racional en la aceptación o rechazo de los principios, concordando con lo planteado por Greene et al. (2004).

Estos datos permiten establecer validez convergente de la escala por la correlación inversa encon-

Tabla IX.

Estadísticos correlacionales entre subescalas y Escala General EAPDP

\begin{tabular}{|c|c|c|c|c|c|c|}
\hline $\begin{array}{l}\text { Escala y Subescalas } \\
\text { (Adhesión) }\end{array}$ & $\begin{array}{l}\text { Graduali- } \\
\text { dad de la } \\
\text { Pena }\end{array}$ & $\begin{array}{c}\text { Derecho al De- } \\
\text { bido Proceso y } \\
\text { Personalidad de } \\
\text { la Pena }\end{array}$ & $\begin{array}{l}\text { Limitación y } \\
\text { Legalidad en la } \\
\text { aplicación de } \\
\text { penas y medidas }\end{array}$ & $\begin{array}{l}\text { Humanidad de } \\
\text { las Penas desde } \\
\text { un Sistema Esta- } \\
\text { tal de Justicia }\end{array}$ & $\begin{array}{l}\text { Principio } \\
\text { de Legali- } \\
\text { dad Penal }\end{array}$ & $\begin{array}{l}\text { Escala Gene- } \\
\text { ral APDP }\end{array}$ \\
\hline Gradualidad de la Pena & & & & & & $\begin{array}{c}0,586^{\star *} \\
0,000\end{array}$ \\
\hline $\begin{array}{l}\text { Derecho al Debido } \\
\text { Proceso y Personalidad } \\
\text { de la Pena }\end{array}$ & $\begin{array}{c}0,260^{* *} \\
0,000\end{array}$ & & & & & $\begin{array}{c}0,736^{\star *} \\
0,000\end{array}$ \\
\hline $\begin{array}{l}\text { Limitación y Legalidad } \\
\text { en la aplicación de } \\
\text { penas y medidas }\end{array}$ & $\begin{array}{c}0,409^{* *} \\
0,000\end{array}$ & $\begin{array}{c}0,385^{\star *} \\
0,000\end{array}$ & & & & $\begin{array}{c}0,660^{* *} \\
0,000\end{array}$ \\
\hline $\begin{array}{l}\text { Humanidad de las Pe- } \\
\text { nas desde un Sistema } \\
\text { Estatal de Justicia }\end{array}$ & $\begin{array}{l}0,183^{*} \\
0,000\end{array}$ & $\begin{array}{c}0,486^{* *} \\
0,000\end{array}$ & $\begin{array}{c}0,345^{* *} \\
0,000\end{array}$ & & & $\begin{array}{c}0,697^{* *} \\
0,000\end{array}$ \\
\hline $\begin{array}{l}\text { Principio de Legalidad } \\
\text { Penal }\end{array}$ & $\begin{array}{c}0,299^{* *} \\
0,000\end{array}$ & $\begin{array}{c}0,550^{* *} \\
0,000\end{array}$ & $\begin{array}{c}0,458^{* *} \\
0,000\end{array}$ & $\begin{array}{c}0,463^{* *} \\
0,000\end{array}$ & & $\begin{array}{c}0,786^{* *} \\
0,000\end{array}$ \\
\hline $\begin{array}{l}\text { Derechos de sociales y } \\
\text { de trato a acusados y } \\
\text { condenados. }\end{array}$ & $\begin{array}{c}0,138^{* *} \\
0,004\end{array}$ & $\begin{array}{c}0,388^{* *} \\
0,000\end{array}$ & $\begin{array}{c}0,150^{* *} \\
0,003\end{array}$ & $\begin{array}{c}0,322^{* *} \\
0,000\end{array}$ & $\begin{array}{c}0,366^{* *} \\
0,000\end{array}$ & $\begin{array}{c}0,580^{* *} \\
0,000\end{array}$ \\
\hline
\end{tabular}

${ }^{* *}$ Significativa al 0,01 (unilateral). 
Tabla X.

Estadísticos correlacionales para validez convergente entre Percepción de Inseguridad y Adhesión a los principios del Derecho Penal (Pearson)

\begin{tabular}{|c|c|c|c|c|c|c|c|}
\hline $\begin{array}{l}\text { Escala y } \\
\text { Subescalas }\end{array}$ & $\begin{array}{l}\text { Gradualidad } \\
\text { de la Pena }\end{array}$ & $\begin{array}{l}\text { Derecho } \\
\text { al Debido } \\
\text { Proceso y } \\
\text { Personalidad } \\
\text { de la Pena }\end{array}$ & $\begin{array}{l}\text { Limitación y } \\
\text { Legalidad en } \\
\text { la aplicación } \\
\text { de penas y } \\
\text { medidas }\end{array}$ & $\begin{array}{l}\text { Humanidad de } \\
\text { las Penas desde } \\
\text { un Sistema Es- } \\
\text { tatal de Justicia }\end{array}$ & $\begin{array}{l}\text { Principio de } \\
\text { Legalidad } \\
\text { Penal }\end{array}$ & $\begin{array}{l}\text { Derechos de So- } \\
\text { ciales y de trato } \\
\text { a acusados y } \\
\text { condenados. }\end{array}$ & $\begin{array}{l}\text { Escala } \\
\text { general } \\
\text { APDP }\end{array}$ \\
\hline $\begin{array}{l}\text { Probabilidad } \\
\text { de ser víctima }\end{array}$ & $-0,155^{\star *}$ & $-0,219^{\star *}$ & $-0,099^{*}$ & $-0,058$ & $-0,144^{* *}$ & $-0,128^{* *}$ & $-0,196^{* *}$ \\
\hline $\begin{array}{l}\text { Preocupación } \\
\text { de ser víctima }\end{array}$ & $-0,144^{* *}$ & $-0,249^{* *}$ & $-0,122^{*}$ & $-0,096^{*}$ & $-0,281^{\text {** }}$ & $-0,172^{* *}$ & $-0,263^{* *}$ \\
\hline
\end{tabular}

${ }^{*} \mathrm{P}<0,05{ }^{* *} \mathrm{P}<0,01{ }^{* * *} \mathrm{P}<0,001$ (Unilateral).

trada entre estas variables, lo que es concordante con lo hipotéticamente esperado. El que estas no presenten mayor fuerza puede indicar, posiblemente, que la APDP podría vincularse con mayor fuerza con otras variables, o bien asociarse de forma indirecta por la presencia de variables intervinientes.

\section{Discusión Y CONCLUSIONES}

Si bien estamos ante un estudio piloto para la construcción del instrumento, la escala presenta adecuadas propiedades de validez factorial exploratoria, lo cual implica que la escala mediría la variable que busca medir en esta primera aproximación. Además, el AFE mostraría que el fenómeno de la Adhesión a los Principios Penales sería multidimensional. Se compondría de seis dimensiones fundamentales a partir de las cuales ha sido posible elaborar subescalas teóricamente coherentes, puesto que han podido ser conceptualizadas y clasificadas consistentemente desde la literatura penal y procesal-penal a través de los diversos autores abordados (Silva 1992; Mir Puig 1994; Ruiz 1997; Bustos y Hormazábal; Etcheberry 1998;Zaffarroni 2001 Bacigalupo 2005;).

Las correlaciones observadas entre subescalas sugieren que, en mayor o menor grado, estas tienden a relacionarse directamente entre sí. Si bien hay diferencias en la fuerza de la correlación, podemos afirmar que la adhesión a alguna subescala no es independiente de la adhesión al resto de las subescalas. En consecuencia, el fenómeno de la adhesión a los principios penales tendería a comportarse consistentemente entre sus dimensiones (lo cual se apoya, además, por la adecuada fiabilidad encontrada entre subescalas). Esto resulta coherente con la teoría, ya que los constructos psicológico-actitudinales tienden a encontrarse correlacionados internamente por la coherencia que presentan en términos direccionales (Rodrígues et al. 2002). Adicionalmente, resultaría consistente con la teoría jurídica, ya que en el Derecho, los principios penales y procesal-penales no constituyen conceptos plenamente separados e independientes, sino que se interrelacionan como sistema en el ordenamiento jurídico (Cordero 2009).
En esta misma línea, los resultados mostrarían evidencias de validez factorial exploratoria, pero futuros estudios debieran orientarse hacia el uso de técnicas confirmatorias (mediante AFC), ya que el estudio piloto se ha centrado en población particular y con una muestra de composición heterogénea, pero no probabilística, siendo una de las principales limitaciones de la investigación. De hecho el sesgo marcado hacia una población con estudios terciarios podría incidir sobre la comprensión de algunos de estos conceptos complejos y/o sobre los resultados descriptivos, lo cual debería tenerse presente en investigaciones futuras.

La Escala General (considerando todos los ítems) tiene una consistencia interna excelente. Pero a nivel de subescalas no todas presentan este nivel. Estas presentan fiabilidades buenas y aceptables siendo sólo una cuestionable (pero con adecuada coherencia teórica). Finalmente, la consistencia entre las seis subescalas es aceptable. Esto indica que los reactivos (y las dimensiones) se correlacionan fuertemente entre sí, pero aportando con información propia y diferenciada para medir el constructo (a nivel de Escala General, subescalas y entre subescalas) con bajo nivel de error de medición (lo cual se facilita por ser un instrumento multi-ítem). Esto permite establecer que no existe sobreestimación en la confiabilidad de la Escala General debido al elevado número de ítems, ya que las subescalas (que tienen menor número de ítems) mantienen fiabilidades adecuadas.

En esta etapa, los análisis permitieron establecer validez convergente, ya que se encontró una correlación inversa entre Adhesión a los Principios Penales y Percepción de Inseguridad. Esto apoya la hipótesis teórica, puesto que se pensó que la aceptación de principios considerados garantistas se encontraría asociada inversamente con la $P I$, ya que los principios supondrían una limitación o barrera a la capacidad del Estado para cumplir con las funciones de seguridad y de orden ante el delito. La debilidad relativa presentada en esta correlación plantea preguntas sobre otras variables posiblemente vinculadas con la APDP y la necesidad de explorarlas en nuevos estudios ( $\mathrm{y}$ que también podrían establecer validez convergente-divergente). 
De este modo, en esta primera aproximación a la medición del fenómeno, se presentarían evidencias de confiabilidad y validez exploratoria para medir adhesión ante delitos de "alto" y "bajo rechazo social" (dentro de los delitos de alta connotación social), pero no para delitos de "rechazo social intermedio" (p. ej. asalto a mano armada) y otro tipo de delitos (estafas de grandes empresas, tráfico de drogas, corrupción, etc.), los cuales no se incluyeron en la medición, puesto que podían encontrarse relacionados con variables que no fueron adecuadamente controladas (tendencia política, apoyo al consumo de drogas, ocupación, etc.). Finalmente, si bien existe adecuada validez de contenido, porque la gran mayoría de los principios fueron medidos, otros en cambio no fueron incorporados explícitamente (p. ej. principio de oportunidad). Estas limitaciones abren nuevas posibilidades de desarrollo del instrumento y de las escalas. Así, los nuevos estudios deberían de considerar la posibilidad de medir la adhesión a los principios penales vinculada a: a) delitos de rechazo social intermedio (robo con violencia, delito de lesiones, etc.), b) delitos de diferente connotación social (terrorismo, estafa grandes empresas, corrupción) utilizando las correspondientes variables de control), c) incorporar algunos principios penales que no fueron medidos (usando similar estructura de pregunta/ respuesta), y/o d) intentar medir adhesión a principios en otras ramas del derecho (tributario, laboral) intentando construir un instrumento similar en la medida en que avance esta línea de investigación.

Disponer de un instrumento y escala con adecuadas propiedades de confiabilidad y validez exploratoria para medir la adhesión a los principios penales resulta fundamental para el desarrollo de la Sociología empírica del Derecho, puesto que permite contar con un modelo que contribuye a conocer las relaciones entre el sistema social y el jurídico.

El principal aporte disciplinar y metodológico de la escala construida reside en el hecho de que esta permitiría medir la adhesión a los principios penales y procesal-penales, pero con bastante independencia respecto a la positivización que estos puedan asumir en el ordenamiento jurídico particular de un país ${ }^{12}$. Esto, porque si bien los ítems han sido elaborados para conocer el consenso o disenso en torno a estos principios dentro del contexto chileno, se mide el grado de aceptación o rechazo a nociones (principios) que son transversales en la legislación de las democracias liberales occidentales presentes en muchos países. Por ello, recordamos la necesidad de avanzar desde el nivel exploratorio hacia el confirmatorio con nuevas poblaciones.

Si bien debe recordarse el carácter piloto del estudio, se ha construido un instrumento potencialmente versátil, ya que eventualmente puede adaptarse a las características contextuales de cada país de acuerdo a su ordenamiento jurídico, institucional o lingüístico ${ }^{13}$, que permite conocer los niveles de consenso o disenso que presenta la ciudadanía en torno a los principios del derecho penal y el procesal-penal.

El estudio de este fenómeno resulta fundamental. Posee implicaciones para la legitimidad del Estado de derecho y la seguridad jurídica propios de una sociedad democrática que tiene a la persona humana y a sus derechos fundamentales como entidades sagradas y protegidas ante la entidad estatal, pero que hoy podrían encontrarse seriamente amenazadas, incluso por la misma voluntad ciudadana.

\section{NOTAS}

1. Descriptivos detallados por subescala/ítem en: https:// pablofuentealbasite.wordpress.com/2017/01/02/ anexos-analisis-factorial-escala-adhesion-a-los-principios-penales/

2. La recolección de datos fue financiada por la Universidad del Desarrollo, Chile.

3. Detalles de la muestra en https://pablofuentealbasite. wordpress.com/2017/01/02/anexos-analisis-factorialescala-adhesion-a-los-principios-penales/

4. Cuento del tío: Tipo de estafa menor. Usa el engaño y astucia aprovechándose de la ingenuidad de la víctima (por ejemplo, cambiar dinero por un boleto de lotería supuestamente premiado). Carterazo o lanzazo: robo por sorpresa; apropiación ilegal de especies sin uso de violencia, aparentando riñas, o maniobras que generen confusión en lugares concurridos.

5. Considerando 19 casos eliminados por 'No respuesta'.

6. Para fundamentar la construcción de la Escapa General de APDP se efectuó un AFE de segundo orden con las seis subescalas. Mediante Análisis Paralelo de Horn se determinó un único factor a extraer (Ejes Principales), que explica el $46 \%$ de la varianza inicial y $37 \%$ postrotación (cargas factoriales sobre 0,400 ).
Esto indica que las seis subescalas poseen una mismo factor común conceptualizable como "Adhesión a los principios del Derecho Penal (y Procesal-Penal)" que englobaría a las seis dimensiones. Adicionalmente, la consistencia interna entre estas seis subescalas es aceptable $(\alpha=0,753)$, indicando que cada subescala reflejaría un concepto común (adhesión a los principios penales), pero que aporta con información diferenciada (no hay correlaciones sobre 0,900 entre subescalas) y con bajo nivel de error de medición. Este análisis permitiría fundamentar la construcción de escalas globales (aditivas o promediadas) sin problemas metodológicos. Considerando que este análisis excede el objetivo de investigación propuesto, este aspecto no será desarrollado con más detalle en este artículo.

7. Resultados pormenorizados del AFE disponibles en https://pablofuentealbasite.wordpress. com/2017/01/02/anexos-analisis-factorial-escala-adhesion-a-los-principios-penales/

8. La "Personalidad de la Pena" presenta una menor coherencia teórica con el factor. No descartamos la posibilidad de eliminar los ítems 9 y 37 en futuros análisis (la consistencia disminuiría a $\alpha=0,779$ ). 
9. Ítems 14 y 40 asociados al aumento de penas y sanciones. Además, estos podrían presentar un componente de actitud punitiva y no solamente de adhesión al principio expuesto.

10. La utilización del término "tratado" en vez de "considerado" o "presumirse" pudo incidir en que este ítem cargase en este factor y no en otro. Se recomienda probar con otro cuestionario utilizando ambas formulaciones.

11. Correlaciones entre factores en https://pablofuentealbasite.wordpress.com/2017/01/02/anexos-analisisfactorial-escala-adhesion-a-los-principios-penales/

\section{Referencias Bibliográficas}

Abad, F. J. et al. 2011. Medición en Ciencias Sociales y de la Salud. Madrid: Editorial Síntesis.

Bacigalupo, E. 2005. Derecho Penal y el Estado de derecho. Santiago de Chile: Editorial Jurídica de Chile.

Bustos, J. y H. Hormazábal. 2004. Nuevo sistema de Derecho Penal. España: Ediciones Trotta.

Chile. 2011. Código Penal. Santiago de Chile: Editorial Jurídica de Chile.

Chile. 2013. Código Procesal-Penal. Santiago de Chile: Editorial Jurídica de Chile.

Chile. 2013. Constitución Política de la República de Chile. Santiago de Chile: Editorial Juridica de Chile.

Cordero Quinzacara, E. 2009. "Los Principios y reglas que estructuran el ordenamiento jurídico Chileno". Ius et Praxis 15: 11-49. http://dx.doi.org/10.4067/S071800122009000200002

Costa Rica. 2015. Convención Americana sobre Derechos Humanos, del 7 al 22 de noviembre de 1969. Disponible en: https://www.oas.org/dil/esp/tratados_b-32_convencion_americana_sobre_derechos_humanos.h̄tm

Cury Urzúa, E. 1982. Derecho Penal. Parte General. Santiago de Chile: Editorial Jurídica de Chile.

D’Adamo, O. y V. García. 2001. "Actitudes y Conducta”. Pp. 287-321 en Psicología Social. Editado por J. Morales, D. Páez, A. Kornblit y D. Asún. Buenos Aires: Prentice Hall.

Etcheberry, A. 1998. Derecho Penal: Parte general. Santiago de Chile: Editorial Jurídica de Chile.

EUA. 2015. Pacto Internacional de Derechos Civiles y Políticos de 16 de diciembre de 1966. Disponible en: http://www. ohchr.org/SP/Professionallnterest/Pages/CCPR.aspx

Ferrari, V. 2012. Derecho y Sociedad. Elementos para una Sociología del Derecho. Colombia: Editorial Universidad Externado de Colombia (edición Kindle).

Fucito, F. 1999. Sociología del Derecho. Del Orden Jurídico y de sus Condicionantes Sociales. Argentina: Editorial Universidad.

Gliem J. y R. Gliem. 2003. "Calculating, Interpreting, and Reporting Cronbach's Alpha Reliability Coefficient for
12. Por ejemplo, con independencia de si el tribunal se encuentra compuesto por un jurado o por jueces, si solo es un juez o es un tribunal colegiado o de la forma bajo la cual se organizan los tribunales, etc.

13. Por ejemplo, modificar el término juez por el de jurado, o sustituir los conceptos de "cuento del tío" o "lanzazo" por la expresión equivalente.

Likert-Type Scales". Pp. 82-88 in Midwest Research to Practice Conference in Adult, Continuing, and Community Education. Columbus: Ohio State University.

Greene, J. D. et al. 2004. "The Neural Bases of Cognitive Conflict and Control in Moral Judgment". Neuron 44: 389400. http://dx.doi.org/10.1016/j.neuron.2004.09.027

Hersh, R., J. Reimer y D. Paolito. 1988. El crecimiento moral, de Piaget a Kohlberg. Madrid: Ediciones Narcea.

Instituto Nacional de Estadísticas. 2015. Actualización de Población 2002-2012 y Proyecciones 2015-2020 Provincia de Concepción. Santiago de Chile.

Kant, I. 2012. Fundamentación para una Metafísica de las costumbres. Madrid: Alianza.

Kant, I. 1879. Principios Metafísicos del Derecho. Madrid: Librería Victoriano Suárez Jacometrezo.

Mazzuco, S. 2012. "Legitimidad, Autonomía y Capacidad: Conceptualizando (una vez más) los poderes del Estado". Revista de Ciencia Política 32: 545-560. http:// dx.doi.org/10.4067/S0718-090X2012000300002

Mir Puig, S. 1994. El Derecho Penal en el Estado Social y Democrático de Derecho. Barcelona: Ediciones Ariel.

Ortega y Gasset, J. 2005. La Rebelión de las Masas. Barcelona: Editorial Espasa-Calpe.

Pardo, A. \& R. San Martín. 2010. Análisis de datos en ciencias sociales y de la salud II. Madrid: Síntesis.

Rodrígues, A., E. Assmar y B. Ablonski. 2002. Psicología Social. México, D.F.: Trillas.

Ruiz, E. 1997. El Derecho Penal Sustantivo y el Proceso Penal. Garantías constitucionales básicas en la realización de justicia. Madrid: Editorial Colex.

Summers, G. 1978. Medición de actitudes. México, D.F.: Trillas.

Silva, J. M. 1992. Aproximaciones al Derecho Penal Contemporáneo. Barcelona: Editorial José María Bosh.

Vièytes, R. 2004. Metodología de la Investigación en Organizaciones, Mercado y Sociedad: Epistemología y Técnica. Buenos Aires: Editorial de las Ciencias.

Zaffaroni, E. 2001. Derecho Penal. Parte General. Buenos Aires: Ediar Editores.

PABLO JAVIER FUENTEALBA CARRASCO es Sociólogo y Magister en Investigación Social y Desarrollo de la Universidad de Concepción (Concepción, Chile). Actualmente es profesor e investigador en el Departamento de Sociología de la Universidad de Concepción, Chile. Dentro de sus áreas de docencia y especialización se encuentran la sociología del Derecho y criminológica, la metodología de la investigación y la filosofía (epistemología, filosofía política y ética).

OMAR A. BARRIGA es Doctor en Sociología (PhD) y Bachelor en Estudios Internacionales de la Ohio State University (Columbus, Ohio, USA). Actualmente es profesor e investigador en el Departamento de Sociología de la Universidad de Concepción, Chile. Sus principales áreas de especialización son metodología de la investigación y estadística social, desviación y delito y problemas sociales del sector pesquero. 